\title{
Sea Bass, Dicentrarchus Labrax Broodstock Management in Underground Water during Gonads Maturation
}

\section{Albattal A*}

Fish Hatching Lab., Aquaculture Division, National Institute of Oceanography and Fisheries (NIOF), Egypt

*Corresponding author: Abdalsalam Albattal, Fish Hatching Lab., Aquaculture Division, National Institute of Oceanography and Fisheries (NIOF), Cairo, Egypt, Tel: +201062583973;

\section{Research Article}

Volume 4 Issue 1

Received Date: February 19, 2020

Published Date: February 28, 2020

DOI: $10.23880 /$ ijoac-16000180

Email: badr_53@yahoo.com

\section{Abstract}

Sea bass, Dicentrarchus labrax broodstock management in underground water. The aquaculture of the sea bass is now well established in Mediterranean countries. However, under culture conditions the sexual maturation is an undesirable process that reduces growth. Improve the reproductive efficiency of marine fishes; enhancing broodstock nutrition with essential nutrients during maturation period actually the key to achieve goal.

Keywords: Fish; Mediterranean Region; Sea Bass; Dicentrarchus Labrax

Abbreviations: FAO: Food and Agriculture Organization; GSI: Gonadosomatic Index; HIS: Hepatosomatic Index; GAFRD: General Authority of Fisheries Resources Development.

\section{Introduction}

The European sea bass (Dicentrarchus labrax) is the most important commercial fish widely cultured in the Mediterranean region. They are characterized by an elongated, silver-grey body with two clearly differentiated dorsal fins and dark spot on the opercula bone. They can grow up to $100 \mathrm{~cm}$ but the most common length is around $50 \mathrm{~cm}$.

FAO [1] ranked sea bass as the second status after Atlantic salmon, not only in the commercial cultivation but also as most popular seafood. Egypt is one of the main Sea bass (Dicentrarchus labrax) producers with annual production of 16,167 tons in 2014 as mentioned by General Authority for Fish Resources Development [2,3]. The exponential growth of marine culture in Egypt is still facing several obstacles. One of these main challenges is the lower quality of hatcheryproduced fry compared with the wild ones, which attributed mainly to low quality of broodstock feeds [4].

From an economical point of view, sea bass is a fish with high commercial value both from capture from wild stocks and from aquaculture production. For this reason, improving the efficiency of the Egyptian marine fish hatcheries to cope with the increasing demand for high quality fry especially for the National fish farming projects is needed; especially no available literature presented the effect of feeding Palaemon sp. to marine broodstock fish.

Broodstock nutrition is one of the most vital research areas of finfish nutrition that need better understanding. An improvement in broodstock nutrition leads to greatly improve not only egg and sperm quality but also seed production (quantity and/or quality).

The spawning process is an energy demand process and is the most stressful event all over the life cycle of fishes; even it occurs as a single spawning event or repeatedly, whereas the broodstock preparation is a critical step in the success of spawning process Accordingly, the problems and deficiencies occurred during the early larvae phases are directly related to the maternal nutrition of broodstock [5]. One of the main priorities in broodstock nutrition is improving the formulated diet quality and reducing the usage of fresh trash fish. Egypt marine aquaculture is a new activity, its current production represents only $5 \%$ of the total aquaculture production as 
reported by FAO [6].

\section{Material and Methods}

The present study aimed to investigate the effect of water quality on the reproductive biology of Sea bass (Dicentrarchus labrax) in underground water during gonads maturation.

\section{Area and Site of Collection}

Seabass (Dicentrarchus labrax) broodstock was collected from El Deeba Triangular Marine Fish Farms District (Domiatte Governorate, Egypt), and rearing in Marine Fish Hatchery (Kilo 21), General Authority of Fisheries Resources Development (GAFRD), Alexandria, Egypt .

\section{Fish Collection}

Male and female Seabass (Dicentrarchus labrax) at various stages of sexual maturity were obtained alive from different sites standard and total lengths of fishes were measured to the nearest $1 \mathrm{~cm}$. Fishes weight was also weighted in nearest grams, and then the following studies were carried out. The gonads were extirpated from the body cavity, weighed to the nearest $1 \mathrm{gm}$. The gonadosomatic index (GSI) and hepatosomatic index (HSI) was calculated for each fish according to the following formula:

GSI = (Weight of the gonads/Weight of gutted fish) X100

HSI = (Weight of the liver/Weight of gutted fish) X100

\section{Histological Preparations}

Immediately after the dissection, the gonads were fixed in Bouin's fluid for $48 \mathrm{hr}$ at room temperature ${ }^{\circ} \mathrm{C}$. The fixed gonads were thereafter dehydrated through graded ethanol solution, cleared and embedded in paraplast (M.P.: $56-58^{\circ} \mathrm{C}$ ). Sagittal sections were made at 3-5 $\mu \mathrm{m}$ thickness. Selected sections were stained with the following techniques: Harris's alum hematoxylin and aqueous solution of eosin as a counterstain [7].

\section{Results}

Like many fish at higher latitudes, the European sea bass life cycle has a seasonal pattern, with annual batch spawning typically occurring during winter months from December to March in the Mediterranean Sea, under low temperature $\left(12-14^{\circ} \mathrm{C}\right)$ and short day length.

Male spermiation lasts longer than spawning in females, which produces 200,000 eggs per kg body weight on average. Eggs are spherical with diameter ranging between 1.2 and 1.4 $\mathrm{mm}$. sexual maturity generally occurs at 3 years in males and 4 years in females in the Mediterranean Sea. Under farming conditions puberty is attained at 2 years in males (average body weight of $200 \mathrm{~g}$ ) and at 3 years in females at $700 \mathrm{~g}$ body weight. This reproductive strategy results in better growth performances in females (39\%) during the second year of life. Sea bass are a gonochoristic species and gonads are undifferentiated during the first year of life (Figure 1).

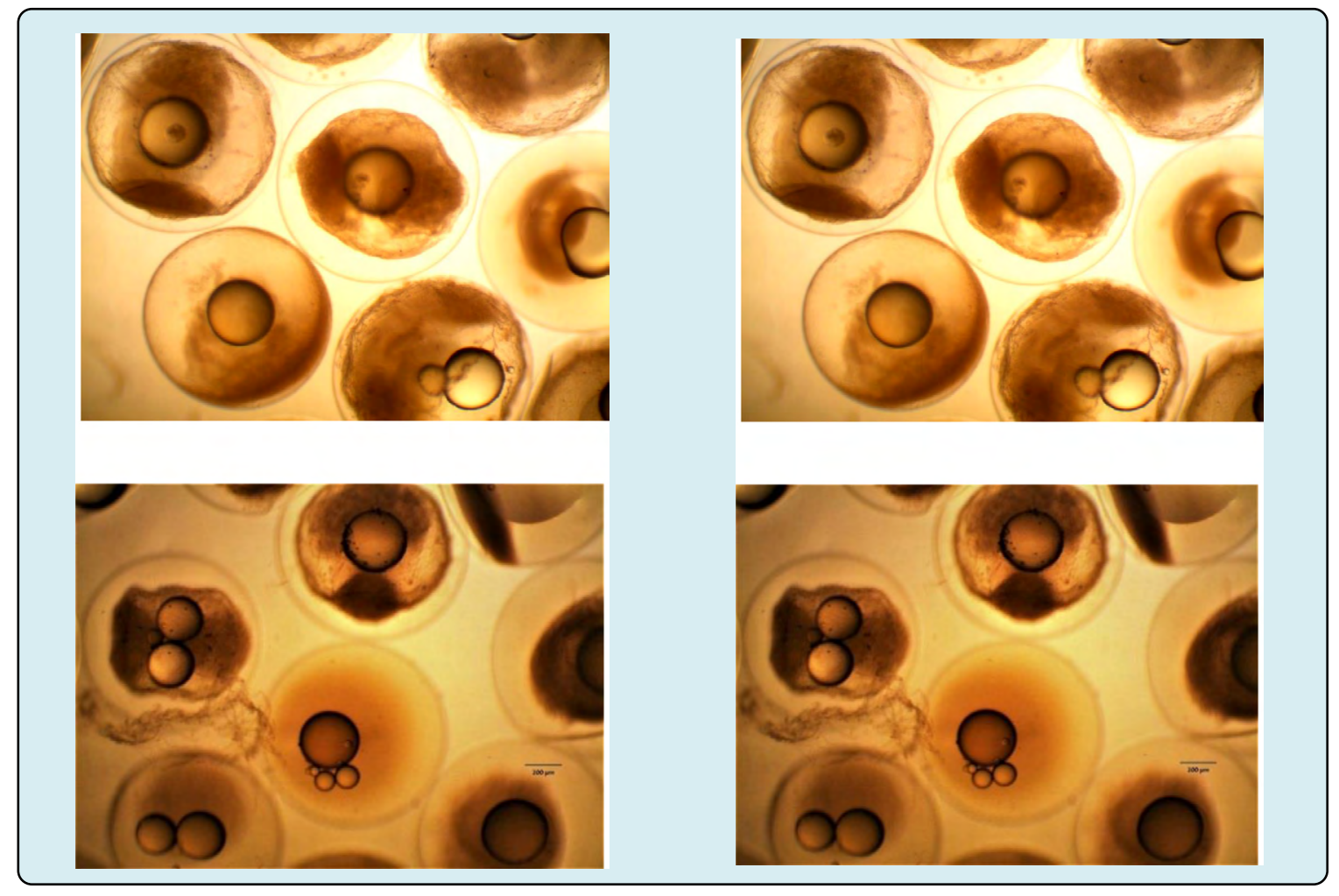




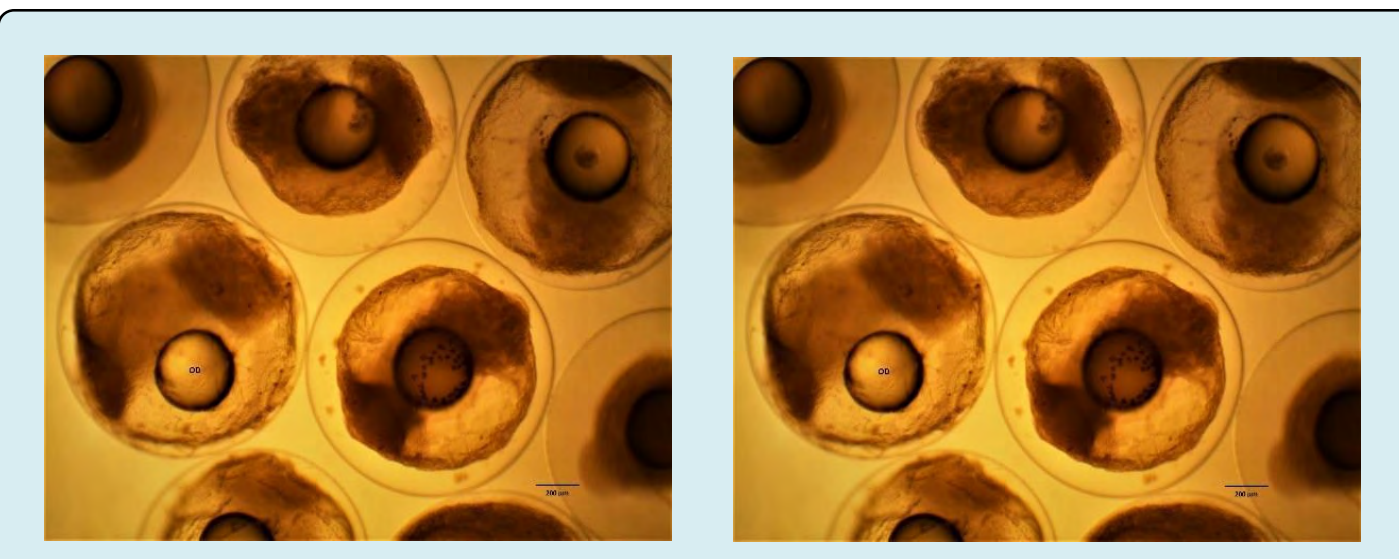

Figure 1: Shape of oil drops in sea bass eggs.

Male biased populations (70-90 \%) are usually produced in cultured conditions, with male fish exhibiting precocious sexual maturation. sea bass spawn once per year in Mediterranean waters, female gonadal maturation starts in September and spawning occurs from December to March in estuaries and in-shore areas where salinity is close to seawater $30 \mathrm{~g} / \mathrm{L}$ and temperature at $12-14{ }^{\circ} \mathrm{C}$.
Spawning is inhibited at temperature below $9{ }^{\circ} \mathrm{C}$ and above $16^{\circ} \mathrm{C}$. Manipulation of day length and temperature are used to alter spawning time, e.g. increased temperature during winter for delaying spawning and low temperature $(<15$ ${ }^{\circ} \mathrm{C}$ ) for synchronization of spontaneous spawning (Table 1 , Graph 1).

\begin{tabular}{|c|c|c|c|}
\hline & & Males & Females \\
\hline March & Sea & $1.52 \pm 0.22$ & $0.55 \pm 0.01$ \\
\hline & Farm & $0.61 \pm 0.07$ & $0.09 \pm 0.01$ \\
\hline May & Sea & $0.04 \pm 0.01$ & $0.11 \pm 0.01$ \\
\hline & Farm & $0.03 \pm 0.02$ & $0.04 \pm 0.01$ \\
\hline Jun & Sea & $0.04 \pm 0.01$ & $0.09 \pm 0.02$ \\
\hline & Farm & $0.04 \pm 0.02$ & $0.05 \pm 0.01$ \\
\hline
\end{tabular}

Table 1: Gonadosomatic (\%) of sea bass in both collections.

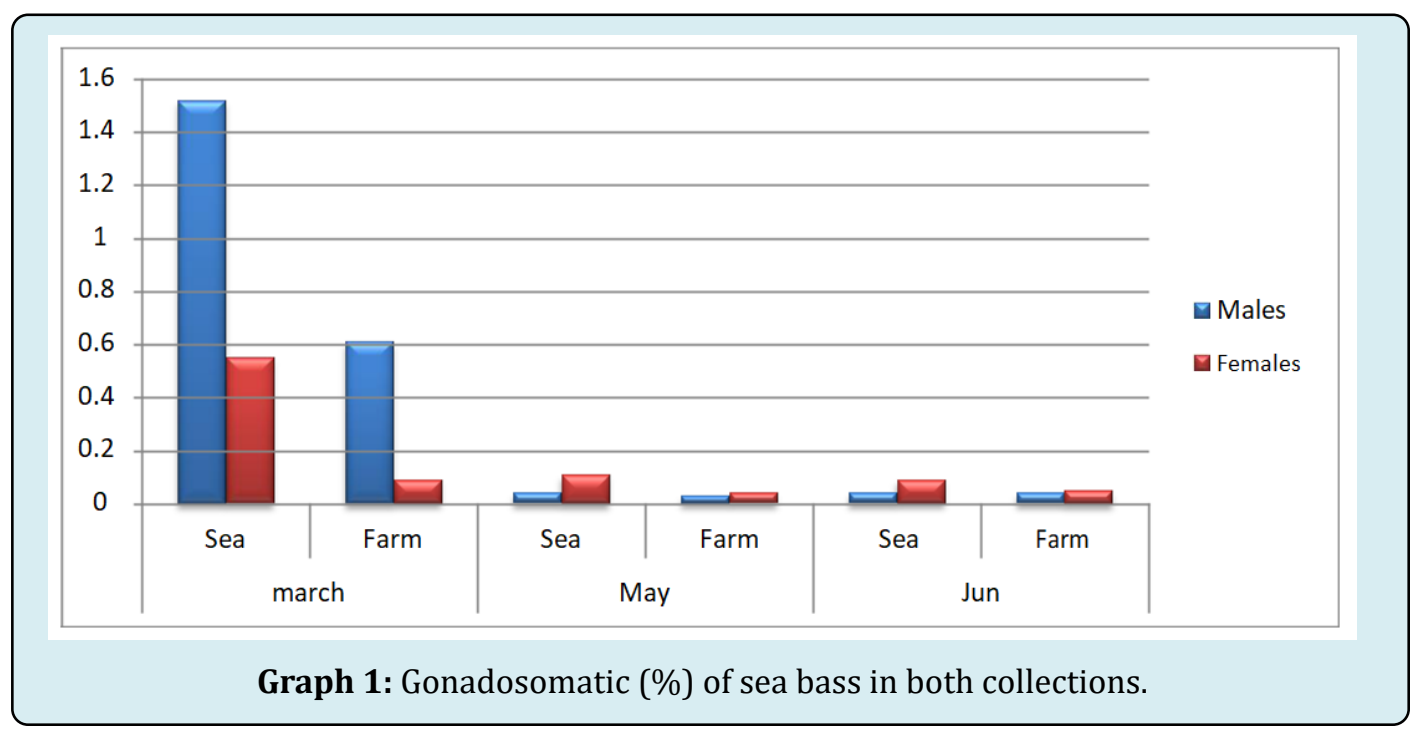




\section{International Journal of Oceanography \& Aquaculture}

Sea bass is a very fecund species and absolute fecundity increasing with body size. Absolute fecundity varies from 293,000 to 358,000 eggs/ $\mathrm{kg}$ body weight in seabass from Atlantic Ocean and from 492,000 to 955,000 eggs $/ \mathrm{kg}$ in Mediterranean seabass [8]. Seabass spawn pelagic eggs, small in size and spherical in shape, its diameter approx 1.15-1.2 mm. Hatching starts approximately 72 hours after fertilization at $14^{\circ} \mathrm{C}$.

\section{Conclusion}

The aquaculture of the sea bass is now well established in Mediterranean countries. However, under culture conditions the sexual maturation is an undesirable process that reduces growth. Improve the reproductive efficiency of marine fishes; enhancing broodstock nutrition with essential nutrients during maturation period is actually the key to achieve this goal. Effects of Artemia and Palaemon supplementation need to studied on European seabass (Dicentrarchus labrax) broodstock egg quality, sexual hormonal and some biochemical indicators.

\section{References}

1. FAO (2012) Cultured Aquatic Species Information Programme. FAO Fisheries and Aquaculture Department, European seabass, Dicentrarchus labrax.

2. GAFRD (2015) Fish statistics yearbook for 2013. Minittry of Agriculture and land Reclamation, General Authority for Fish Resources Development, Egypt.

3. GAFRD (2011) General Authority for Fish Resources Development. Fish statistics book, pp: 107.

4. Srour TM, Essa MA, Abdel-Rahim MM, Mansour MA (2016) Replacement of Fish Meal with Poultry Byproduct Meal (PBM) and its effects on the Survival, Growth, Feed Utilization, and Microbial Load of European Seabass, Dicentrarchus Labrax fry. Global Advanced Research Journal of Agricultural Science 5(7): 293-301.

5. Izquierdo MS, Fernandez Palacios $H$, Tacon AGJ (2001) Effect of Broodstock nutrition on reproductive performance of fish. Aquaculture 197(1-4): 25-42.

6. FAO (2015) Globefish highlights. A quarterly update on world seafood markets quarterly issue, including JanMar 2016 statistics.

7. Conn HJ (1953) Biological stains, Williams and Wilkins Company, Baltimore.

8. European Food Safety Authority (2008) Animal Welfare Aspects of Husbandry Systems for Farmed European seabass and gilthead seabream. Scientific report of EFSA prepared by Working Group on seabass/seabream welfare. Annex I to The EFSA Journal 844: 1-21. 